\title{
$\alpha$-SMA Expression Increased Over Cell Passages and Decreased by Exogenous TGF- $\beta 1$, In Vitro Studies on Myofibroblast Derived from Orbital Socket Contracture
}

\author{
Debby Shintiya Dewi *, Elsa Safira Chairinnisa, Hidayat Sujuti, Diana Lyrawati, Tinny Endang Hernowati
}

Department of Ophthalmology, Faculty of Medicine, Brawijaya University, Malang, Indonesia

\begin{abstract}
$\alpha$-smooth muscle actin ( $\alpha$-SMA), a marker of myofibroblast, induces cytoskeleton reorganization, increases contractility and stimulates cell migration in TGF- $\beta 1$ induced stress fibers. The aims of the present study were to determine the level of $\alpha$-SMA expression and morphological cell changes in different passages of myofibroblasts with varied TGF- $\beta 1$ concentrations. Myofibroblast cell cultures were derived from fibrotic tissues of fourth degree socket contracture. The $\alpha$-SMA expression level was measured in myofibroblast cultures passage I, II, and III with and without $10 \mathrm{ng} / \mathrm{mL}$ TGF- $\beta 1$, and in passage III with $2.5 ; 5 ; 10$; and $20 \mathrm{ng} / \mathrm{mL}$ TGF- $\beta 1$. Results: The levels of $\alpha$-SMA expression level in passage I to III were I $31.42 \pm 3.4 ; 40.34 \pm 8.14$ and $56.37 \pm 7.57$, respectively. Addition of $10 \mathrm{ng} / \mathrm{mL}$ TGF- $\beta 1$ into passage I-III myofibroblast cultures resulted in $\alpha$-SMA expression level of $31.24 \pm 2.93 ; 36.81 \pm 6.09$; and $14.29 \pm 2.72$, respectively. Myoblasts passage III showed the lowest $\alpha$-SMA expression level following exposure to TGF- $\beta 110 \mathrm{ng} / \mathrm{mL}(22.37 \pm 12.86)$ and highest without TGF- $\beta 1(48.34 \pm 13.36)$, however no morphological changes detected. $\alpha$-SMA expression level increased with cell passages, decreases with addition of TGF- $\beta 1$ while not affecting morphology of myofibroblast derived from the orbital socket contracture.
\end{abstract}

Keywords: TGF- $\beta 1, \alpha-S M A$, fibrotic, eye, socket, contracture

\section{INTRODUCTION}

Orbital socket contracture is a wrinkled state of anophthalmic socket, thus, it cannot fit the prosthesis. The incidence of socket contracture was reported as $7.7 \%$ of the overall anophthalmic socket [1]. Our study, at dr. Saiful Anwar General Hospital Malang, Indonesia, in 2007, however, showed that the occurrence of socket contracture was $32.25 \%$ overall, mostly 5 years post-eye removal $(60 \%)[2]$.

Our study showed that application of Mitomycin C during and after socket reconstruction surgery prevented eye socket contracture recurrences in 50\% cases [3]. In one case report, the socket contracture did not recur on a patient undergoing 7 repair surgeries within one year with the use of $0.04 \%$ Mitomycin C intra- and post-operatively [4]. Prevention of recurrence of this case may be explained provided that the molecular mechanism of socket contracture has been known.

*Corresponding author:

Debby Shintiya Dewi

Department of Ophthalmology, Faculty of Medicine, Brawijaya

University

Jalan Veteran, Malang, Indonesia 65145

E-mail: shintdebby@gmail.com
The socket contracture formed fibrotic tissue and granulation due to chronic irritation, one of which due to friction of the prosthesis with the socket, resulted in impairment of wound healing process $[5,6]$. The formation of hypertrophic scars that dominates the socket contracture tissue is a deviation of wound healing in the form of hyperactivity of fibroblast, excessive formation of myofibroblasts and extracellular matrix (ECM) deposition $[7,8]$

TGF- $\beta$ plays roles in all phases of eye wound healing process by increasing growth factor secretion involved in cell migration, proliferation, ECM deposition and myofibroblast formation. Increased growth factor activity not only leads to an increase in wound healing rate, but also a higher risk for scar formation. Therefore, TGF- $\beta$ is one of the most potential targets for scarring intervention $[8,9,10,11]$.

Currently, the definite pathogenesis of socket con-

\section{How to cite:}

Dewi DS, Chairinnisa ES, Sujuti $H$ et al. (2018) $\alpha$-SMA

Expression Increased Over Cell Passages and Decreased by Exogenous TGF- $\beta 1$, In Vitro Studies on Myofibroblast Derived from Orbital Socket Contracture J. Trop. Life. Science 8 (2): 200 -205 . 
tracture has not been clearly elucidated and may involve many factors. Studies on fibrosis were mostly performed using tissues other than socket contracture. Among few studies on socket contracture, one has demonstrated that myofibroblasts play an important role in modulating wound healing, tissue remodeling and organ deformation [12]. TGF- $\beta 1$ is a major profibrotic cytokine and increased expression plays an important role in the deposition of collagen and extracellular matrix, wound healing and scar formation in the socket contracture tissue [6]. TGF- $\beta 1$ is a key mediator that induce $\alpha$ - SMA $[11,12]$.

Alpha-smooth muscle actin ( $\alpha$ - SMA) may serve as a reliable marker for myofibroblast cells [12], although others considered it as not a consistent marker for contractile fibroblasts and lots of collagen [13]. Alpha-SMA widely presents in stressed fibers induces cytoskeleton reorganization, increases contractility and stimulates cell migration. Stress fibers contracts myofibroblasts such as in muscle movements.

Myofibroblast cells morphologically resembling fibroblasts and smooth muscle cells, rich in cytoplasmic microfilament (actin-rich stress fibers) and $\alpha$-SMA expression. Fibroblasts appear on day 2-3 following injury, while myofibroblasts appear on day 12 when wound contractions are nearly $80 \%$ complete $[11,12]$.

In the present study, we reported our in vitro study determining the level of $\alpha$-SMA protein expression in myofibroblasts derived from orbital socket contracture and whether addition of TGF- $\beta 1$ may affect $\alpha$-SMA expression and morphology of such myofibroblasts. Since passage number of cells passaged several times may affect protein expression, we also determined whether passage number alone, with or without addition of TGF$\beta 1$, affect the level of $\alpha$-SMA expression in myofibroblast passages [14].

\section{MATERIALS AND METHOD}

\section{Sample of myofibroblast}

This study was conducted in November to December 2017 at Ophthalmology Department-dr. Saiful Anwar Hospital and Central Laboratory of Life Sciences - Brawijaya University, Malang. The study design was approved by the Ethics Committee of dr. Saiful Anwar General Hospital and followed the guidelines of the Declaration of Helsinki.

The inclusion criteria for the patient was orbital socket contracture (degree $1-5$ ) with medical indication for surgical socket reconstruction. The selected patient was based on signed informed consent to partici- pate in the study. The sample of this study was fibrotic tissue removed from a patient with fourth degree socket contracture.

Primary culture of myofibroblast was prepared from patient with socket contracture surgery [15]. Each tissue was cut into pieces approximately $1 \AA \sim 1 \mathrm{~mm}$ in size, placed in 12 well plastic culture plates in DMEM with $50 \mathrm{U} / \mathrm{mL}$ of penicillin, $50 \mathrm{~g} / \mathrm{mL}$ streptomycin and $10 \%$ FCS, and incubated at $37^{\circ} \mathrm{C}$ in a humidified (95\%) incubator under $5 \% \mathrm{CO}_{2}$. Cell culture media were changed thrice weekly. Upon reaching confluence, cells were trypsinized with $0.25 \%$ trypsin/EDTA solution in phosphate buffered saline (PBS) and passaged in $25 \mathrm{~cm} 2$ plastic cell culture flasks. Cells were cultured further for this study, or passaged 2-3 times and used directly for experiments, or harvested, resuspended in freezing media and stored frozen in $-80^{\circ} \mathrm{C}$ until used. For experiments, a series of cells passaged I-III were cultured for 3 weeks and incubated 24 hours with or without the addition of $10 \mathrm{ng} / \mathrm{mL}$ TGF- $\beta 1$. Another series of experiments were performed using cells passage III, cultured for 3 weeks and incubated 24 hours with the addition of $2.5 ; 5 ; 10$; or $20 \mathrm{ng} / \mathrm{mL}$ TGF- $\beta 1$.

\section{Measurement of $\alpha-S M A$ level and myofibroblast mor- phology}

The expression levels of $\alpha$-SMA were measured in passage I, II, III without and with the administration of TGF- $\beta 110 \mathrm{ng} / \mathrm{mL}$ as well as in passage III with TGF$\beta 12.5,5 \mathrm{ng} / \mathrm{mL}, 10$ and $20 \mathrm{ng} / \mathrm{mL}$.

The $\alpha$-SMA expression level was measured with anti $\alpha$-SMA antibody [1A4, Cat. number ab7817, Abcam]. Cells were fixed with paraformaldehyde, permeabilized with $0.1 \%$ Triton X-100 and blocked with $3 \%$ BSA for 30 minutes at $25^{\circ} \mathrm{C}$. Samples were incubated with primary antibody $(1 / 400$ in $1 \times$ TBS $)$ for 3 hours at $25^{\circ} \mathrm{C}$. An Alexa Fluor ${ }^{\circledR 633-c o n j u g a t e d ~ G o a t ~}$ anti-mouse IgG polyclonal $(1 / 500)$ was used as the secondary antibody. Fluorescent images of $\alpha$-SMA myofibroblasts were acquired in red channel using $400 \times$ magnification, $0.5 \%$ power of excitation lines, and gain set at 850 of the laser scanning confocal microscope (CLSM FV1000, Olympus Corp., Waltham, MA). Confocal images of the fluorophores were analyzed using Olympus Fluoview ver.4.2a software. $\alpha$-SMA expression was measured in arbitrary unit (AU). Cells were observed also morphologically using $100 \times$ magnification with inverted microscope Olympus IX 71 and 400× magnification with CLSM FV1000. 


\section{Data analysis}

The results were analysed using IBM SPSS version 2.0 statistical analysis application. The data analysis in the passage group with TGF- $\beta 1$ exposure using ShapiroWilk normality test, followed by ANOVA or KruskalWallis test, and post-hoc Tukey or Mann-Whitney test to know differences between each group. Results were considered statistically significant when $\mathrm{p}<0.05$.

\section{RESULTS AND DISCUSSION}

\section{Effect of the number of passage on $\alpha$-SMA level}

The level of $\alpha$-SMA expression increased with increasing passage number, with values of $31.42 \pm 3.4$, $40.34 \pm 8.14$ and $56.37 \pm 7.57$ arbitrary unit (Figure 1).

Addition of $10 \mathrm{ng} / \mathrm{mL}$ TGF- $\beta 1$ in cell culture decreased $\alpha$-SMA level only in passage III $(\mathrm{p}=0.000)$. Values of $\alpha$-SMA level in each group was $31.24 \pm 2.93$; $36.81 \pm 6.09$; and $14.29 \pm 2.72$ arbitrary unit for passage I-III, respectively (Figure 2).

Microscopically, different passage with or without addition of TGF- $\beta 1$ did not change cell morphology (Figure 3).

When different passages were compared between with and without addition of TGF- $\beta 1$, our results showed that the most pronounced effects were seen on passage III and with addition of TGF- $\beta 1$ (Figure 4). On passage III, addition of TGF- $\beta 1$ decreased a-SMA expression up to three folds.

Effect of TGF- $\beta 1$ concentration added on a-SMA expression was studied using passage 3 of myofibroblast primary culture from socket contracture. The results showed that compared to the myofibroblast without TGF- $\beta 1$, only $10 \mathrm{ng} / \mathrm{mL}$ TGF- $\beta 1$ decreased significantly $\alpha$-SMA expression level $(\mathrm{p}=0.000)$. The a-SMA expression level was $48.34 \pm 13.36 ; 46.45 \pm 47.04 ; 38.07 \pm 9.54$; $22.37 \pm 12.86$; and $29.80 \pm 13.33$ in cell culture with TGF- $\beta 10 ; 2.5 ; 5 ; 10$; and $20 \mathrm{ng} / \mathrm{mL}$, respectively (Figure $5)$.

Our study demonstrated that passaging influence $\alpha-S M A$ level on myofibroblast primary culture derived from orbital socket contracture tissue. Similar results were reported by Kinner et.al. (2001) that levels of $\alpha$ SMA are increasing following the number of passages or passages performed. One of the main factors of physiological change from fibroblasts to myofibroblast is a mechanical tension. [16] According to Wakatsuki et.al. (2000) there is progressive increase in matrix rigidity overtime if the tissue experienced a tension, including in our present study during passaging process. [17] Our study demonstrated that following passage and cultured

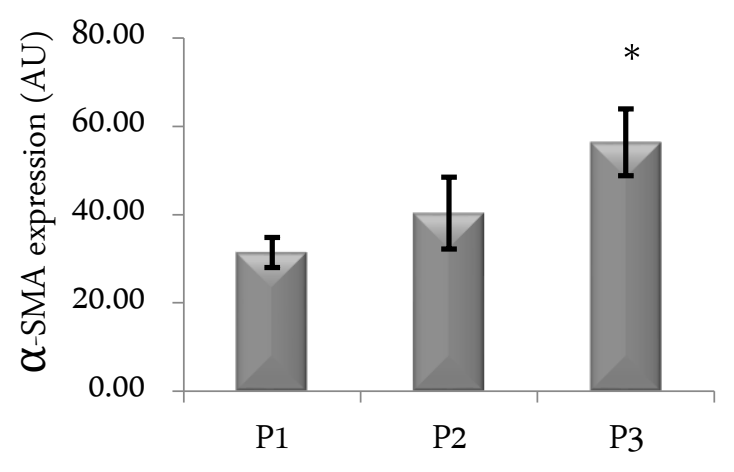

Figure 1. Level of $\alpha$-SMA in cell culture with different passage $(\mathrm{P} 1, \mathrm{P} 2, \mathrm{P} 3)$ without TGF- $\beta 1$

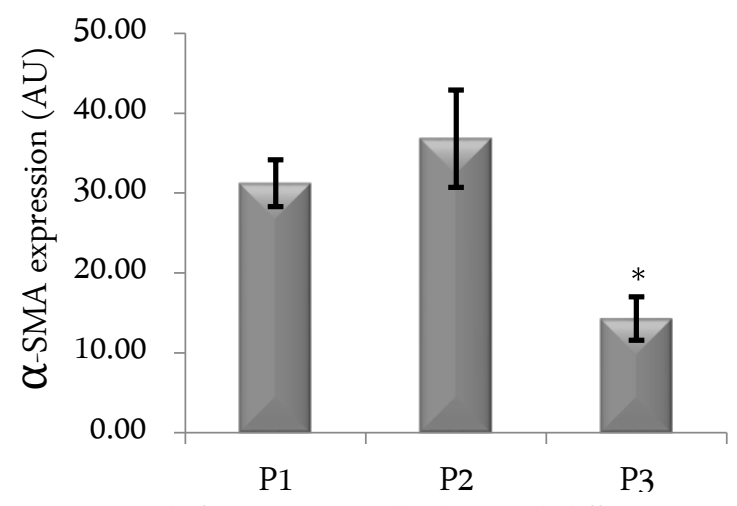

Figure 2. Level of $\alpha$-SMA III in cell culture with different passage (P1, P2, P3) with addition of $10 \mathrm{ng} / \mathrm{mL}$ TGF- $\beta 1 .{ }^{*} \mathrm{de}-$ notes significantly different compared to $\mathrm{P} 1(\mathrm{p}=0.000)$

without addition of TGF- $\beta 1$, a pro-fibrotic factor, myofibroblasts remained the same morphological while the $\alpha-S M A$ level increased. Probably, the passaging process itself induce stress response, which may increase the production of endogenous TGF- $\beta 1$, subsequently induced $\alpha$-SMA expression, even without exogenous TGF- $\beta 1$. [18] Thus, the myofibroblast, a differentiated phenotype, did not convert into fibroblasts, an inactive phenotype of cells. [19] During physiological wound healing process, myofibroblasts undergo apoptosis. [20, $21,22,23]$.

On the contrary, the addition of exogenous TGF- $\beta 1$ on passage 3 resulted in significantly low $\alpha$-SMA. In such case, others reported that TGF- $\beta 1$ may activate TGF- $\beta 1$ receptor, however, instead of inducing $\alpha$-SMA expression, it activates focal adhesion kinase (FAK). Further, FAK binds integrins, fibronectin and collagen which all have roles as cell adhesion receptors in myofibroblast differentiation. [24]. Another study also reported that TGF- $\beta 1$ did not always induce $\alpha$-SMA expression. In the presence of synthetic hyaluronan (HA) 

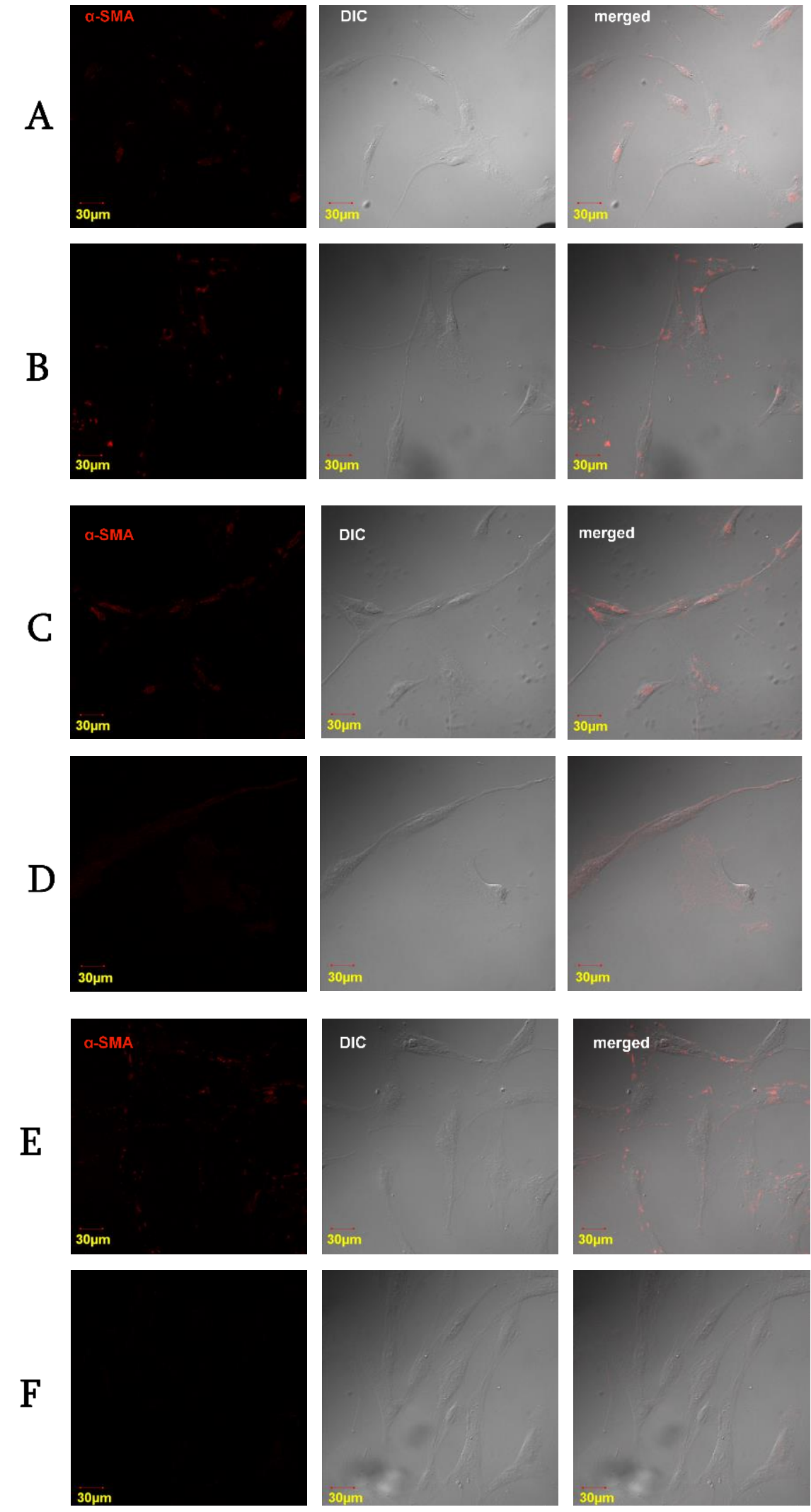

Figure 3. Confocal microscopic observations. Bright field view (left), red filter immunofluorescent view for $\alpha$-SMA (middle), and the merged view of both (right). Passage I (A), passage I with TGF- $\beta 1$ 10ng/ml (B), passage II (C), passage II with TGF$\beta 110 \mathrm{ng} / \mathrm{mL}$ (D), passage III (E), passage III with TGF- $\beta 110 \mathrm{ng} / \mathrm{mL}$ (F). Different passages and addition of TGF- $\beta 1$ did not resulted in observable changes on cells morphology 


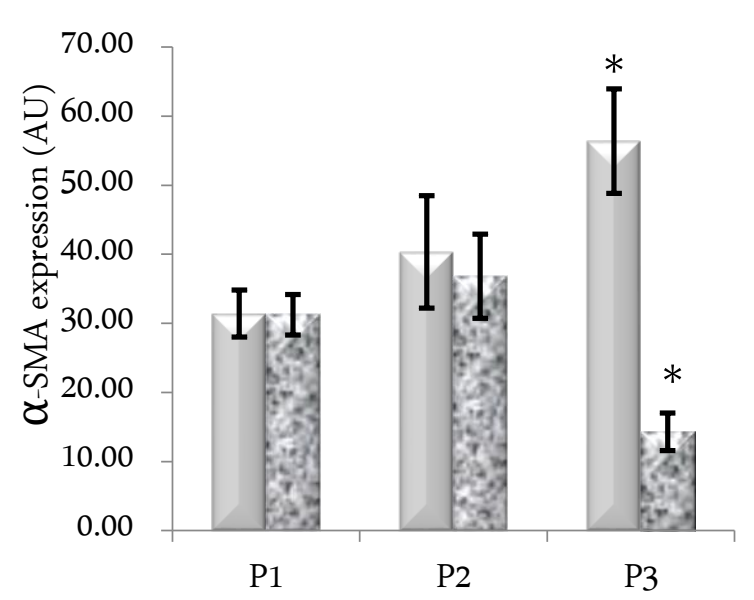

$\square_{\text {without TGF- }} \beta_{1} \quad 10 \mathrm{ng} / \mathrm{mL} \quad \square$ with TGF- $\beta 110 \mathrm{ng} / \mathrm{mL}$

Figure 4. Effect of passage and addition of TGF- $\beta 1$. Significant effects were seen on passage 3 with and without 10 $\mathrm{ng} / \mathrm{mL}$ TGF- $\beta 1$ addition.

myofibroblast differentiation was inhibited without decreasing TGF- $\beta 1$ receptor expression. [25]. Further studies are required to clarify whether FAK activation causes $\alpha$-SMA degradation and apoptosis of myofibroblasts, or other pathways causing TGF- $\beta 1$ decreased $\alpha$-SMA.

\section{CONCLUSION}

Passage number increased whereas TGF- $\beta 1$ could decrease $\alpha$-SMA expression levels in dose-dependent fashion, however, both did not affect morphology of myofibroblast culture derived from orbital socket contracture. Therefore, in vitro experiments to study myofibroblast from orbital socket contracture should consider passage number and level of TGF- $\beta 1$.

\section{ACKNOWLEDGMENT}

The authors wish to thank staff at Central Laboratory of Life Science, Brawijaya University for technical assistance in confocal microscopy. This study receives no external funding.

\section{REFERENCES}

1. Adhikari RK, Khazai H, Usha KD (2007) Prospective evaluation of contracted sockets. Kathmandu University Medical Journal 5 (3): 391 - 395.

2. Lestari AT, Dewi DS, Sadono EG (2008) Pattern and management of contracted socket in Saiful Anwar Hospital Malang: A retrospective study. Makassar, Indonesian Ophthalmology Meeting.

3. Suharyanto Y, Dewi DS (2012) Mitomycin-C Application in contracted socket reconstruction: A retrospective study. Ma- lang, Department of Ophthalmology, dr. Saiful Anwar General Hospital/Faculty of Medicine, Brawijaya University.

4. Dewi DS (2012) Successful of mitomycin C application in the reconstruction of recurrent contracted socket: A case report. In the 27th Asia Pasific Academy of Ophthalmology Congress: 13 - 16 April 2012; Busan.

5. Stroncek JD, Reichert WM (2008) Overview of wound healing in different tissue types. In: Reichert WM eds. Indsumuraning neural implant: Strategies for contending with the in vivo environment. Boca Raton (FL), CRC Press.

6. Kurtul BE, Erdener U, Mocan MC et al. (2014) Clinical and impression cytology findings of amniotic membrane and oral mucosal membrane transplantation for the management of socket contracture. International Journal of Ophthalmology. 7 (2): $340-344$.

7. Su WH, Cheng MH, Lee WL et al. (2010) Nonsteroidal antiinflammatory drugs for wound: pain relief or excessive scar formation? Mediators of Inflammation 2010: 413238. doi: 10.1155/2010/413238.

8. Li P, Liu P, Xiong R et al. (2011) Ski, a modulator of wound healing and scar formation in the rat skin and rabbit ear. Journal of Pathology 223 (5): 659 - 671. doi: 10.1002/path. 2831.

9. Ellis JS, Paull DJ, Dhingra S et al. (2009) Growth factors and ocular scarring. European Ophthalmic Review 3 (2): 58 63. doi: 10.17925/EOR.2009.03.02.58.

10. Falke LL, Gholizadeh S, Goldschmeding R et al. (2015) Diverse origins of the myofibroblast-implications for kidney fibrosis. Nature Review Nephrology 11 (4): 233 - 244. doi: 10.1038/ nrneph.2014.246.

11. Stahnke T, Kowtharapu BS, Stachs O et al. (2017) Suppression of TGF- $\beta$ pathway by pirfenidone decreases extracellular matrix deposition in ocular fibroblasts in vitro. PLoS ONE. 12 (2): e0172592. doi: 10.1371/journal.pone.0172592.

12. Tawfik HA, Abdulhafez MH, Osman WM (2016) Revisiting the role of the myofibroblast in socket surgery: An immunohistochemical study. Ophthalmic Plastic and Reconstructive surgery 32 (4): 292 - 295. doi: 10.1097/IOP.0000000000000 510.

13. Sun K, Yongen C, Reed NI, Sheppard D (2016) Alphasmooth muscle actin is an inconsistent marker of fibroblasts responsible for force-dependent TGF-beta activation or collagen production across multiple models of organ fibrosis. American Journal of Physiology Lung Cell Molecular Physiology 310: L824 - L836.

14. Pan GJ, Chang ZY, Schöoler HR, Pei DQ (2002) Stem cell pluripotency and transcription factor Oct4. Cell Research 12 (1): 321 - 329. doi: 10.2213/cl121321.

15. Callahan MA, Callahan A (1984) Correction of the abnormal soft tissue socket. In: Stewart WB, ed. Ophthalmic plas- 
tic and reconstructive surgery. San Francisco, American Academy of Ophthalmology. pp. $351-352$.

16. Kinner B, Spector M (2001) Smooth muscle actin expression by human articular chondrocytes and their contraction of a collagen glycosaminoglycan matrix in vitro. Journal of Orthopaedic Research 19 (2): 233 - 241. doi: 10.1016/S0736 0266(00)00081-4.

17. Wakatsuki T, Kolodney MS, Zahalak GI, Elson EL (2000) Cell mechanics studied by a reconstituted model tissue. Biophysical Journal 79 (5): 2353 - 2368. doi: 10.1016/S00063495(00)76481-2.

18. Hinz B (2015) The extracellular matrix and transforming growth factor- $\beta 1$ : Tale of a strained relationship. Matrix Biology 47: 54 - 65. doi: 10.1016/j.matbio.2015.05.006

19. Manapov F, Muller P, Rychly J (2005) Translocation of p21 Cip1/WAF1 from the nucleus to the cytoplasm correlates with pancreatic myofibroblast to fibroblast cell conversion. Gut 54 (6): 814 - 822. doi: 10.1136/gut.2003.036491.

20. Darby IA, Laverdet B, Bonté F, Desmoulière A (2014) Fibroblasts and myofibroblasts in wound healing. Clinical, Cosmetic and Investigational Dermatology 7: 301 - 311. doi: 10.2147/CCID.S50046.

21. Tomasek JJ, Gabbiani G, Hinz B et al. (2002) Myofibroblasts and mechano-regulation of connective tissue remodelling. Nature reviews. Molecular Cell Biology 3 (5): 349 - 363. doi: 10.1038/nrm809.

22. O'Connor JW, Mistry K, Detweiler D et al. (2016) Cell-cell contact and matrix adhesion promote $\alpha$ SMA expression during TGF $\beta 1$-induced epithelial-myofibroblast transition via Notch and MRTF-A. Scientific Reports 6: 26226. DOI: $10.1038 /$ srep 26226 .

23. Negmadjanov U, Holmuhamedov A, Emelyanova L et al. (2016) TGF- $\beta 1$ increases resistance of NIH/3T3 fibroblasts toward apoptosis through activation of $\mathrm{Smad} 2 / 3$ and $\operatorname{Erk} 1 / 2$ pathways. Journal Patient-Centered Research and Reviews 3: 187 - 198. doi: 10.17294/2330-0698.1407.

24. Thannickal VJ, Lee DY, White ES et al. (2003) Myofibroblast differentiation by Transforming Growth Factor-1 is dependent on cell adhesion and integrin signaling via focal adhesion kinase. The Journal of Biological Chemistry 278 (14): 12384 - 12389. doi: 10.1074/jbc.M208544200.

25. Chen X, Thibeault SL (2012) Response of fibroblasts to transforming growth factor-b1 on two-dimensional and in three-dimensional hyaluronan hydrogels. Tissue Engineering: Part A 18 (23 - 24): 2528 - 2538. doi: 10.1089/ten. tea.2012.0094. 